\title{
O FUTURO COMO RUPTURA: A CRÍTICA MATERIALISTA-HISTÓRICA DE FICÇÃO CIENTÍFICA E UTOPIA ${ }^{1}$
}

\author{
Elton Luiz Aliandro Furlanetto
}

Quando nos debruçamos sobre o estudo da Utopia, tanto na sua acepção de tradição literária, quanto na sua conotação política e em seu aspecto filosófico, percebemos que estamos diante de uma linha de estudos que se estende durante vários séculos. Contudo, uma série de esforços cognitivos vem sendo feitos por alguns estudiosos nos últimos trinta anos, de modo a sintetizar essa linha de pensamento e extrapolar sobre os limites e potencialidades do pensamento, inerentes a qualquer tempo histórico. Esse corpo de estudiosos nos trazem novas formas de analisar antinomias, de interpretar as contradições históricas e de sistematizar o mundo.

Como afirmado, a linha de pensamento que criou utopias e as analisou remonta séculos. Muitos autores estabelecem $A$ República de Platão como o primeiro modelo de discussão sobre uma sociedade que não existia empiricamente, e que visava exercitar, ao menos teoricamente, uma forma alternativa de organização social. A partir dele, temos algumas

1 Este artigo é uma versão ampliada e revisada de uma fala para o Simpósio sobre Utopia, ocorrido na UNICAMP em 2011. Também, tratei do assunto na introdução de minha dissertação de mestrado Reificação e Utopia na Ficção Científica norte-americana da Guerra Fria. 2010. Disponível em: http://www.teses.usp.br/teses/disponiveis/8/8147/ tde-27042010-121239/pt-br.php 
obras, até chegar Utopia, publicada em 1516 pelo inglês Thomas More, que cunha o termo que será utilizado para estabelecer todo um cânone de obras similares. Não somente na literatura e na filosofia, os séculos XVIII e XIX contaram com uma tentativa de organizar empiricamente comunidades que agiam na contracorrente do fluxo imposto por suas sociedades. Elas se diziam utópicas e foram tanto inspiradoras quanto fortemente combatidas.

No século XX, uma das formas adotadas pelo impulso da utopia de criticar o mundo atual e pensar em alternativas a ele coube à ficção científica. Assim, podemos identificar uma crescente onda de obras ficcionais e estudos que mesclam os dois gêneros. Surgem, em diversas partes do mundo, um corpo heterogêneo de obras literárias que, em muitos aspectos lembras as utopias clássicas, mas delas se diferenciam substancialmente. Seguindo-se a elas, uma nascente tentativa de interpretar tais obras aparece no horizonte, principalmente da academia. No contexto de língua inglesa, temos uma série de obras que foram publicadas nos últimos anos, e são elas que serão analisadas adiante. Parece se tratar de uma tradição ainda pouco difundida em terras nacionais. De modo geral, meu texto será uma espécie de síntese de alguns dos autores que podem trazer insights interessantes para o estudo geral da ficção científica e da utopia no Brasil.

Primeiramente, entretanto, gostaria de estabelecer um recorte inicial em meu levantamento. Vou me focar no contexto norte-americano, exceto ao me referir ao iugoslavo Darko Suvin, que, não obstante, escreveu em inglês e passou parte importante da sua vida como professor no Canadá, onde viveu durante os anos que publicou suas obras mais importantes. Em segundo lugar, restringirei as minhas observações a um grupo bem específico de autores, ou seja, àqueles ligados à tradição materialista histórica ou marxista.

Isso acontece porque há uma ligação importante entre a esquerda e a ficção científica e utopia. No âmbito literário, uma grande parte dos escritores desses gêneros usou suas construções estéticas como forma de comentar e polemizar sua realidade social, criticando o sistema sócioeconômico vigente e sugerindo alternativas em potencial para eles. Tal ligação nem sempre foi harmoniosa, desde que, apesar de suas obras demonstrarem seus alinhamentos com propostas críticas da sociedade, muitos autores rejeitavam as políticas de esquerda, engajando-se em posições políticas mais liberais e, até mesmo, conservadoras. No âmbito da crítica, fica mais marcado que os gêneros chamaram a atenção de diversos grupos de intelectuais, entre os quais aqueles mais fortemente associados à Nova Esquerda e aos estudos marxistas, que enxergavam nas 
obras, formas de mobilizar ou imobilizar energias de crítica, resistência, engajamento e luta.

Tal linha de pensamento nos leva a estabelecer novamente um recorte: o crítico Gary Westfahl afirmou, em seu artigo para a revista Science Fiction Studies, que desde o começo do século XX, a fortuna crítica dos gêneros em questão se compunha basicamente de sinopses, resenhas, fanzines, cartas de leitores, editoriais, correspondências pessoais, encontros e convenções, estudos críticos publicados por pequenas editoras, introduções, prefácios e artigos publicados por editores, leitores, escritores e fãs. Essa perspectiva é consequência de um processo histórico de fechamento da ficção científica em um campo especializado, na década de 1920 (WESTFAHL, 1999). Não será esse tipo de crítica que nos interessará discutir.

Em meados do século, podemos localizar uma segunda corrente a qual aponta os anos 1960 como ponto inicial. Antes desse período, a crítica acadêmica de ficção científica já acontecia, mas de forma bastante fragmentada e individual. Segundo Donald Hassler, em seu ensaio sobre os primeiros críticos da ficção científica, "mesmo que Philip Babcock Gove, J.O. Bailey, Marjorie Hope Nicolson, Thomas D. Clareson, e outros estivessem começando a construir carreiras acadêmicas a partir do estudo (parcial) da ficção científica, eles o faziam como pioneiros solitários e auto-suficientes" (HASSLER, 1999). Seu foco mantinha a herança da crítica dita popular, que parecia "inspirad[a] pela idéia de fazer a ficção científica 'respeitável', dando a ela ancestralidade distinta e um propósito social claro.” (JAMES, 2001, p. 20)

Podemos dizer que a tradição crítica deu um passo fundamental com os critical journals dedicados à área da ficção científica ou especulativa (segundo alguns preferem se referir a ela). Um dos primeiros foi The Newsletter of the Conference on Science Fiction of the MLA, organizado por Tom Clareson, iniciado em 1959. Depois dele, temos na Inglaterra o Foundation e nos Estados Unidos o Extrapolation, até que em 1973, é lançado o Science Fiction Studies. Publicado até os dias de hoje, o SFS trouxe à luz, desde seu lançamento, trabalhos intelectuais diversos que colaboraram com um estudo profundo sobre vários aspectos do gênero: história, formas, conteúdos (o que pensamos serem categorias indissociáveis).

Assim, gostaria de apontar na direção de certos estudiosos que contribuíram de modo central para o desenvolvimento teórico de tais periódicos e da crítica do gênero. São sujeitos singulares, inseridos em um contexto da Nova Esquerda, atentos às novas tendências da crítica cultural. O primeiro deles será Darko Suvin ${ }^{2}$. Apresentarei um resumo de 
sua obra por meio indireto, devido à dificuldade de acesso a ela: os livros encontram-se ora indisponíveis ora esgotados. Usarei os apontamentos feitos sobre ela no livro Scraps of the Untainted Sky, de Tom Moylan, sobre quem escreverei adiante.

Em 1972, com o ensaio "On the Poetics of the Science Fiction Genre", Darko Suvin estabelece uma abrangente análise teórica e histórica da ficção científica. Através da dialética, ele define a ficção científica nos termos de uma literatura 'não-realista', mas, simultaneamente, uma variação moderna que "se reapropriou e refuncionalizou qualidades da escrita naturalista” (MOYLAN, 200o, p. 42). Além disso, o estudioso apresentou os pontos de contato entre a ficção científica e subgêneros anteriores que também recusavam relatos imediatos do mundo como um fato e, por conseguinte, geravam figurações e contextos 'radicalmente diferentes'. Ainda que ligando a ficção a modos míticos, fantásticos e nãonaturalistas, Suvin fundamenta a diferença entre esses gêneros e a ficção científica na sensibilidade realista da última, ou ainda, no "supostamente factual (...) rigor científico extrapolativo e totalizante” (SUVIN apud MOYLAN, 2000, p. 43) que é imputado à ficção científica.

Como resultado de sua teorização, ele chega à seguinte definição:

um gênero literário cujas condições necessárias e suficientes são a presença e interação do estranhamento e da cognição, cujo principal mecanismo formal é uma estrutura imaginativa alternativa ao mundo empírico do autor... ela se distingue pela dominância ou hegemonia narrativa do novum (novidade, inovação) validado pela lógica cognitiva. (MOYLAN, 2000, p. 42)

Como uma espécie de resumo de sua teoria, esta máxima traz vários conceitos que foram posteriormente problematizados e reavaliados, mas sempre mantidos nessa relação dialética. Vejamos o que cada um implica:

O conceito de estranhamento provém de duas fontes: ele remete ao ostranenie dos formalistas russos e ao Verfremdung de Brecht. Já para Suvin, estranhamento é, antes de tudo, "a escolha de um enredo que seja não-realista, já que ele é determinado pelo novum.” O segundo termo

2 Segundo Wegner (2011), Suvin é conhecido pelo público americano e europeu por sua obra em duas vertentes: primeiro, como crítico fundador da revista Science Fiction Studies, e por todos os seus ensaios sobre utopia(nismo), ficção científica e fantasia. Suvin "teve um papel central no estabelecimento da ficção científica como um campo legitimado e importante da pesquisa acadêmica” (WEGNER, 2011, p. 9). Além disso, Suvin também serviu como divulgador, nos meios anglófonos, das ideias do dramaturgo alemão Bertolt Brecht. Outros aspectos que seus ensaios vão tratar são a teoria crítica, a epistemologia política, a globalização e a literatura asiática (especialmente a japonesa). 
que consta na definição de Suvin sobre a ficção científica é a cognição ou a lógica cognitiva. Aqui, temos o elemento que separa a ficção científica do mito, da fantasia, já que a cognição concede racionalidade ao mundo imaginado e é o que o conecta ao mundo empírico. Essa categoria também recebeu críticas e reformulações na própria obra de Suvin. A princípio, posto que o processo de cognição estava relacionado à "domesticação do estranho" com objetivo de torná-lo familiar, ele denegaria e excluiria o incrível e o implausível do campo de conhecimento. Porém, o crítico decide expandir o campo de cognição, que antes excluía a cognição nãoracional para uma ideia de que "toda criatividade humana, seja poética ou científica, racional ou emocional, conceitual ou não-conceitual, tem potencial cognitivo"(PARRINDER, 2001, 46). Como consequência, temos que a criatividade vira conhecimento.

Além disso, Suvin separa a noção de cognição como forma de razão crítica da "atualmente co-optada e comprometida razão instrumental" (MOYLAN, 200o, p. 46), que nada mais é senão uma ferramenta do capitalismo.

Através do novum, portanto, o estranhamento é materializado e se torna cognitivo: eis a estratégia formal que diferencia o conteúdo da obra de ficção científica do mundo empírico do autor, servindo não apenas para localizar as tendências disponíveis em certo momento histórico, mas também, para apontar possíveis diretrizes radicalmente novas, em latência, naquele momento. É esta categoria do novum que vai determinar a consistência e relevância das relações presentes na narrativa.

Porém, o novum como categoria formal sofreu críticas e foi revisada pelo próprio Suvin (MOYLAN, 2000, p. 46-7). O crítico Tom Moylan explica que existiam motivos extraconceituais para tais críticas, justificando a eventual rejeição do conceito, já que o novum é uma categoria totalizante validada pela lógica cognitiva, surgindo no apogeu do vigor pós-estruturalista dos anos de 1980, que era avesso a operações totalizantes (identificadas com totalitárias). Tais correntes teóricas identificavam a cognição como racionalismo prescritivo e reducionista. Igualmente, Suvin apontou que não havia nenhuma relação entre o novum e a "novidade", tão cara ao sistema capitalista. Ele chamou este impulso da mercadoria de pseudo-novum, afinal, o processo de troca de mercadorias depende da rápida circulação e consequente necessidade de desenvolvimento de (aparentemente) novos produtos e imagens/ conceitos.

Além disso, Suvin rejeita as ligações entre o novum e o conceito reificado de "progresso" burguês. A própria fonte do conceito de novum, Ernst Bloch, sofreu uma falsa interpretação parecida, já que seu conceito 
do "impulso utópico da esperança" foi reinterpretado como a falsa utopia de que "a nova ordem do mercado oferece o lugar primordial para as experiências individuais de luta, sucesso e prazer" (MOYLAN, 2000, p. 47). Assim, Suvin se alinha a Bloch no uso do conceito e na negação da forma burguesa e reificada de 'progresso'. Além disso, em sua obra, o crítico dá conta de perceber que os espaços de contestação e ação política, que o novum tende a representar, são múltiplos e cambiantes, dando conta de possibilidades emergentes e inconclusas. Aqui as influências de Suvin são Antonio Gramsci e Raymond Williams.

O que podemos inferir, então, a partir do resumo de Moylan é que Suvin consegue teorizar a dupla função da ficção científica que é a de entreter e educar (respectivamente por intermédio do estranhamento e da cognição). Ela o faz por meio de um elemento formal legitimamente histórico, chamado novum, que nos permite entender a instância criativa, dinâmica e inconclusa da obra de uma forma mais completa.

Dito isso, gostaria de levar a discussão a outro autor, Fredric Jameson, que, em contato com os trabalhos de Suvin, também vem contribuindo, nas últimas décadas, com ensaios que têm relação próxima com a análise aqui presente. Jameson é bastante conhecido na academia, tanto nos Estados Unidos quanto no Brasil. Muito dos seus livros têm publicação brasileira e recentemente ele foi agraciado com um prêmio de reconhecimento internacional pela qualidade do conjunto de sua obra para as ciências humanas. Porém, devido ao seu marxismo militante (e seu interesse pela totalidade) e ao seu estilo dialético e "difícil" de ler, ele é criticado diversos setores da academia.

Não obstante, sua contribuição para o campo é essencial, visto que o utópico é seu conceito mestre, segundo O’Donnell (2007, p. 215). Fazendo um levantamento de textos importantes sobre o conceito de utopia, temos teremos dois ensaios e uma obra mais extensa, na qual ele fará uma espécie de síntese da sua reflexão sobre o assunto. Aqui não será a oportunidade de apresentar com detalhes o percurso teórico de Jameson, principalmente na sua mais recente obra sobre utopia, mas apenas trazer à luz alguns dos textos que deveriam fazer parte do cânone crítico daqueles interessados no conceito, no impulso ou, principalmente, no gênero literário utópico. ${ }^{3}$

3 Para uma análise mais aprofundada sobre a relação de Jameson com a utopia, é possível ler alguns dos textos escritos para o periódico Utopian Studies de 1998, cuja temática era exatamente esta. Alguns desses textos constam da minha bibliografia. Outra possibilidade é a leitura de resenhas críticas para Archaeologies of the Future com as de Fitting, Cevasco ou O’Donnell. 
O primeiro texto será "Of Islands and Trenches: Neutralization and the Production of the Utopian Discourse" de 1977. O texto é um comentário sobre o livro de Louis Marin, Utopiques: Jeux d'Espaces. Aqui Jameson estabelece os pontos que definem a Utopia, principalmente na chave do que ele chama de neutralização. $\mathrm{O}$ autor enxerga o gênero da utopia, mais como uma práxis do que como um modo de representação. Ele explica que a estrutura utópica é uma "alusão ponto-a-ponto geralmente na forma de inversões - que fazem a leitura da utopia ser um processo de deciframento alegórico" (JAMESON, 1977, p. 7). O que acontece é que ao passo que tais alusões são produzidas e reforçadas, a presença do "real" acaba por ameaçar a Utopia, que está tentando neutralizar ou se diferenciar do mundo empírico. Em resumo, ele aponta que enquanto a esquematização da Utopia tende a se afastar do mundo como ele é, e negá-lo, ele precisa aludir a ele e nessa alusão, ela corre o risco de ser cancelada. Assim, Jameson foca a atenção no processo de excluir o que não serve para a Utopia - como o dinheiro e a violência (que fica nas mãos dos mercenários) ao passo que a reestabelece do lado de fora do círculo que forma a República. Assim, o gênero vai se basear na exclusão que, em última instância reverte o esforço do discurso utópico em provar ou demonstrar que esta complicada e impossível exclusão é ela mesma "imaginável”. O ponto final de Jameson é estabelecer a utopia portanto, seguindo Marin, por sua negatividade:

O assunto mais profundo de Utopia, e a fonte de tudo que é mais interessante politicamente sobre ela, é precisamente nossa inabilidade em concebê-la, nossa incapacidade de produzi-la como visão, nosso fracasso em projetar o outro do que é, como quando fogos de artifício dissolvem na escuridão do céu noturno, nos deixando sozinhos novamente com esta história (JAMESON, 1977, p. 21, itálico meu)

Em 1988, Fredric Jameson publicou o ensaio "Cognitive Mapping”, cujo objetivo era mapear as possibilidades de uma nova estética que fosse capaz de questionar a lógica e a prática sócio-econômicas do capitalismo tardio. Moylan relembra que mesmo não tendo uma relação explícita com a ficção científica, o ensaio trata exatamente do potencial utópico do gênero. Segundo Jameson, é necessária "uma estética que, embora dialética, vá além dos limites do modernismo e pós-modernismo, mas, mantendo as características tradicionais de ser capaz de 'ensinar, comover e dar prazer"' (MOYLAN, 200o, p. 56-7). Assim, o cognitivo ganha um novo fôlego e torna-se central em sua análise da cultura. Para tanto, Jameson argumenta que cada fase de transformação do capital possui um espaço social característico: o capitalismo clássico teve por 
característica transformar o espaço heterogêneo dos feudos e reinos em uma homogeneidade cartesiana, através do processo dos cercamentos; no capitalismo de monopólio, o social excede o individual, já que o império se distende em âmbito global e as contradições entre sujeito e sociedade se acirram. Afinal, o terceiro momento, o capitalismo tardio, aparta do indivíduo a experiência. Ele já não consegue dar conta da verdade do sistema; então, os macro-processos políticos, econômicos que estruturam a existência social e a vida cotidiana se distanciam. Se a totalidade das relações se torna indisponível ao sujeito, "a causa ausente [de tais relações]... nunca pode emergir na presença da percepção" (JAMESON apud MOYLAN, 200o, p. 57), ou seja, no nível da percepção subjetiva, o funcionamento do sistema se torna tão abstrato que, ainda que se perceba uma causa - a contradição que forma e subjaz o sistema -, sua totalidade é individualmente irrepresentável.

Jameson vê no "mapeamento cognitivo" uma ferramenta para coordenar ou mediar essa impossibilidade de representar, "por meio de representações conscientes ou inconscientes" que permitem análises, interpretações, reutilizações. Somente uma noção de totalidade das relações sociais permite a chance de imaginar a possibilidade de mudança de tal sistema (levando em conta que o processo seria interessante tanto no nível do indivíduo quanto aos projetos políticos coletivos). Portanto, a busca por uma forma de integrar o modo em que vivemos a uma visão materialista de transcendência é vital. Jameson admite que ela deve ter um aspecto

social e cultural, envolvendo a tarefa de imaginar como uma sociedade sem hierarquia, uma sociedade de pessoas livres, uma sociedade que tenha de uma vez por todas repudiado o mecanismo econômico do mercado, possa de alguma forma fazer coerência. (JAMESON apud MOYLAN, 200o, p. 6o)

Em suma, a tarefa de imaginar algo que ainda não existe, mas que faça coerência, sendo a priori idealmente e racionalmente realizável, de forma a integrar a experiência vivida no cotidiano ao horizonte utópico das possibilidades de mudança (o transcendente), numa chave não apenas no âmbito individual e sim, coletivo, liga este ensaio à discussão a respeito da função, definição e interpretação crítica da ficção científica e da arte em geral.

Finalmente, Jameson publicou outros ensaios, que foram reunidos no ano de 2005, com a publicação do livro Archaeologies of the Future (Arqueologias do Futuro, sem tradução para o português), cujo subtítulo revela suas preocupações centrais - A Desire Called Utopia and 
Other Science Fictions (Um Desejo Chamado Utopia e Outras Ficções Científicas). Dividido em duas partes - como o próprio livro de More, a primeira foi escrita posteriormente e serve para organizar os argumentos da segunda -, o bloco inicial traz um estudo profundo da definição de Utopia, seu papel filosófico, político e literário. A segunda reúne ensaios sobre diversos aspectos e autores de ficção científica (incluindo Brain Aldiss, Ursula LeGuin, Vonda McIntyre, A.E. Van Vogt, Phillip K. Dick, Kim Stanley Robinson e William Gibson) e utopia que foram escritas no decorrer dos últimos trinta anos. A densidade teórica e o fôlego quase sobre-humano do crítico americano desembocam naquilo que Maria Elisa Cevasco chama de "um dos programas políticos mais produtivos para a crítica cultural engajada nos dias de hoje”. (CEVASCO, 2011). Tratase do último capítulo da primeira parte do livro, chamado "Future as Disruption" (Futuro como Ruptura), que é o resumo de todo o livro, onde todos os temas são retomados e o teórico aponta para o futuro. Evitando dar uma resposta ou resolução, na medida em que não "existe nenhuma historicamente disponível", ele aponta que encarar as antinomias que formam o nosso modo de existir, mais do que dar falsas soluções para elas é um caminho para conseguirmos socialmente transcender o presente fragmentado e fraturado.

Na ficção científica, assim, o caráter utópico é maximizado pelas possibilidades que o futuro apresenta como "ruptura", não apenas no âmbito individual ou tecnológico, mas no sentido da transcendência em direção a um novo paradigma de existência.

Por questões de recorte, evitarei uma listagem muito grande de outros autores e obras que são bastante importantes nos estudos de utopia e deveriam constar nas bibliografias dos cursos e nas discussões sobre utopia. Vou me concentrar em apenas três delas.

O primeiro deles, publicado em 2000, é o já citado Scraps of the Untainted Sky (Destroços do Céu Imaculado) de Tom Moylan, pesquisador atualmente responsável pelo Ralahine Center for Utopian Studies, na Universidade de Limerick. Neste livro, especificamente, o autor faz um mapa historiográfico abrangente dos estudos de ficção cientifica e da utopia nos últimos 50 anos, apresentando uma vasta bibliografia e um poder de síntese invejável, sem simplificar demais assuntos complexos, ainda que seu impulso didático busque elucidar os textos mais obscuros. Grande parte de seu livro discute conceitos como os de "utopia crítica" e "distopia crítica”, nos seus aspectos estéticos e políticos. A primeira parte do livro foca nos estudos acadêmicos da utopia e da ficção científica. Ele começa apresentando os conceitos que formam o protocolo de leitura da ficção científica (o novum, por exemplo). Em seguida, Moylan 
traça as relações entre os elementos chave da pesquisa sobre ficção científica e utopia, tanto na tentativa de buscar um paradigma, quanto na ênfase que ele dá a ousadia de tentar sonhar. Ele resume o trabalho de alguns autores, entre os quais Suvin e Jameson, e até seu próprio esforço anterior para compreender principalmente a natureza da utopia, denominado Demand the Impossible (Exija o Impossível, sem tradução para o português), publicado em 1985 .

É curioso notar que nesse volume, como acontece em Scraps, ainda que em medidas diferentes, o autor começa a delinear alguns capítulos sobre a genealogia da utopia literária. Desses, ele passa a uma análise dos elementos formais e, finalmente, traz alguns capítulos que mostram na prática suas ferramentas e pressuposições teóricas em uso. Percebemos que tal estrutura visa atender duplamente aqueles que buscam a teoria, mas precisam de exemplos mais concretos para que tal teoria faça sentido. Os romances que Moylan seleciona para exemplificar seus pontos acerca do que seria a "utopia crítica" são Female Man (1975), de Joanna Russ, The Dispossessed (1974), Woman on the Edge of Time, de Marge Piercy e Triton de Samuel Delaney. Trata-se de produtos de uma determinada conjuntura histórica (a dizer, os movimentos feministas dos anos 1960 e 1970), chamam atenção no contexto brasileiro pela sua ausência: quase nenhum deles foi traduzido nos últimos quarenta anos (a exceção é Os Despossuídos, que possuem uma tradução pela Nova Fronteira de 1978), ainda que tenhamos experimentado um renascimento do interesse pelos estudos de utopias e mesmo com o fortalecimento dos estudos de gênero e dos grupos de mulheres nas universidades nacionais. Vários podem ser os motivos que levaram tais livros ao ostracismo no país. Uma das possibilidades seria o estilo mais experimental característico a quase todos eles, com abundantes jogos de linguagem, mas, principalmente, por seus conteúdos políticos mais explícitos.

Já na segunda parte de Scraps, Moylan fala sobre a "virada para a distopia"4. Trata-se de uma complementação histórica de sua outra obra, visto que ele percebe nos movimentos dos anos 1980 e 1990 um desmonte das políticas e das conquistas das décadas anteriores por governos de direita. Tais mudanças político-econômicas são sentidas na arte, quando os autores, para se manterem fiéis a uma verdade histórica, abandonam a utopia crítica e tendem a produzir obras distópicas. Então, o autor explica sobre as diferenças entre a distopia e a anti-utopia, chegando a desenvolver o conceito de distopia crítica, ou seja, aquela que se mantém

4 No original é o capítulo chamado “The Dystopian Turn”. 
aberta (open-ended), e que traz traços de utopia em vez de simplesmente negar qualquer tipo de esperança.

Na terceira parte, Moylan nos apresenta alguns estudos de caso: cada capítulo se organiza por uma análise de autores, principalmente exemplos do que ele chama de distopia crítica. São eles Marge Piercy, Kim Stanley Robinson e Octavia Butler. Novamente, ele constrói seu cânone usando autores e obras que são pouco conhecidas no Brasil e, portanto, seu livro é uma boa porta de entrada para interessados em ficção científica e utopia que ainda não conhecem esses autores mais engajados.

O livro apresenta um panorama, principalmente do ponto de vista de um historiador dos estudos do gênero. Apesar de um pouco maçante nas primeiras partes, nas quais a teoria toma corpo, o livro é importante como tentativa de resumir a trajetória dos estudos de utopia nos Estados Unidos e apontar alguns caminhos e possibilidades para onde a pesquisa pode ir. Sua bibliografia é uma rica fonte dos mais diversos aspectos, temas e artigos na área, podendo ser usada como um trampolim para diversos tipos de abordagens (especialmente as mais politizadas).

O segundo autor relevante para nosso campo de pesquisa é Phillip Wegner, professor da Universidade da Flórida. Tendo sido orientando de Jameson, ele busca seguir os passos do mestre na busca de posicionar a utopia como um conceito central para entender a modernidade. Um de seus livros mais importantes é Imaginary Communities, publicado em 2002, cujo subtítulo é Utopia, a Nação, e as Histórias espaciais da Modernidade. Seus estudos partindo da Utopia de Morus, passando por Bellamy, Zamyatin, Bogdanov, Orwell e Jack London, vão desembocar em reflexões acerca de utopias modernas tais como Os Despossuídos de Ursula Le Guin. Todos aqueles que estudam os clássicos e seus diversos desdobramentos atuais não podem deixar de lê-lo. Segundo o autor, ele busca defender a realidade das comunidades imaginadas, ou seja, "fazer uma reconsideração da modernidade em termo de suas 'histórias espaciais"' (WEGNER, 2002, p. xiv). Para Wegner, a realidade das utopias está não em sua existência nos dias de hoje, mas "no que elas têm de efeitos materiais, pedagógicos e, em última instância, políticos, moldando os modos com que as pessoas compreendem, e como consequência, agem em seus mundos."(WEGNER, 2002, p. xvi)

A terceira, diferente em escopo das outras não parte de um analista da literatura. Trata-se de Espaços de Esperança do economista David Harvey, que foi traduzida no Brasil pela editora Loyola. A obra que pode suscitar questionamentos a partir de um estudo sobre as utopias não está diretamente ligado com os estudos literários da utopia. De uma forma 
didática e consistente, o autor parte de uma análise do espaço cotidiano, da história da modernidade, para explicar como a utopia está inserida em diversos espaços e como ela é neutralizada pelos mecanismos do sistema capitalista. Ainda que o foco seja na arquitetura e na economia, parte de sua análise foca nas construções literárias utópicas e o epílogo é nada menos que um exercício de especulação imaginativa, no qual Harvey se imagina sonhando e no seu sonho viaja para uma comunidade futura, que ele inventa e comenta. Ele mistura ficção ao seu relato mais histórico e factual, dando sinal de que, como Jameson, a imaginação política pelo que não é, mas poderia ser, deve estar sempre colocada como uma possibilidade.

Certamente, as obras elencadas aqui são apenas algumas no enorme corpo de produções dos últimos anos e elas provavelmente levarão os pesquisadores a novas descobertas bibliográficas até então desconhecidas ou pouco exploradas em território nacional. São obras inspiradoras e, com exceção da de Harvey, esperam tradução e divulgação nos meios acadêmicos ou para todo o tipo de leitor interessado em entender os meandros da utopia e da ficção científica.

\section{REFERÊNCIAS BIBLIOGRÁFICAS}

CEVASCO, Maria Elisa. Archaeologies of the Future. In Situations: Project of the Radical Imagination. Vol 2, No 1 (2007). Disponível em: http://ojs.gc.cuny.edu/index.php/ situations/article/view/284/211. Acessado em: 10-11-2011.

FITTING, Peter. Fitting, Peter. "Fredric Jameson and anti-anti-Utopianism." Arena Journal 25-26 (2006): 37. Academic OneFile. Disponível em: < http://go.galegroup. $\mathrm{com} / \mathrm{ps} / \mathrm{i} . \mathrm{do}$ ?id=GALE\%7CA151317772\&v=2.1\&u=gain40375\&it=r\&p=AONE\&sw=w > Acessado em: 15-10-2012.

FITTING, Peter. "The Concept of Utopia in the Work of Fredric Jameson.” Utopian Studies (1998): pp. 8-17. General OneFile. Disponível em: < http://go.galegroup. $\mathrm{com} / \mathrm{ps} / \mathrm{i} . \mathrm{do}$ ?id=GALE\% $7 \mathrm{CA} 53280207 \& \mathrm{v}=\mathbf{2 . 1} \& \mathrm{u}=\mathrm{gain} 40375 \& \mathrm{it}=\mathrm{r} \& \mathrm{p}=\mathrm{ITOF} \& \mathrm{sw}=\mathrm{w}>$ Acessado em: 28-09-2012.

FURLANETTO, Elton Luiz Aliandro. Reificação e Utopia na Ficção Científica norteamericana da Guerra Fria. Dissertação de Mestrado. Universidade de São Paulo. 2010. Disponível em: http://www.teses.usp.br/teses/disponiveis/8/8147/tde27042010-121239/pt-br.php. Acessado em 13-04-2012

HARVEY, David. Espaços da Esperança. Tradução de Adail Ubirajara Sobral e Maria Stela Gonçalves. São Paulo, Edições Loyola, 2004. 
HASSLER, Donald. "The Academic Pioneers of Science Fiction Criticism, 19401980". In: SCIENCE Fiction Studies. (JulHo, 1999). Disponível EM: www.depauw. edu/sfs/backissues/78/hassler78art.htm ACESSADO EM: 05-05-2009.

JAMES, Edward. "Before the Novum". In: Learning from other worlds: estrangement, cognition and the politics of Science Fiction and Utopia. Durham, Duke University Press, 2001.

JAMESON, Fredric. 1977 Of Islands and Trenches: Neutralization and the Production of Utopian Discourse. Diacritics 7:2 (Verão1977), pp. 2-21. . Archaeologies of the Future: The Desire called Utopia and Other Science Fictions, London and New York, Verso, 2005

O'DONNELL, Liam A. Preserving the Possibility of the Impossible. In: Cosmos and History: The Journal of Natural and Social Philosophy, vol. 3, no. 1, 2007. pp. 215225. Disponível em: <http://www.cosmosandhistory.org/index.php/journal/article/ viewFile/62/123> Acessado em: 12-10-2012

MOYLAN, Tom. Scraps of the Untainted Sky. Colorado, Westview Press, 200o. (tradução nossa)

PARRINDER, Patrick. "Revisiting Suvin's Poetics of Science Fiction". In: Learning from other worlds: estrangement, cognition and the politics of Science Fiction and Utopia. Durham, Duke University Press, 2001.

SUVIN, Darko. Positions and Pressupositions in Science Fiction. Kent, Kent State University Press, 1988.

WEGNER, Phillip. Imaginary Communities. Berkeley, University of California Press, 2002. . "Foreword: Crossing the Border with Darko Suvin." In SUVIN, Darko. "Suvin Illuminated: A Life in Letters." Paradoxa 23. 2011

WESTFAHL, Gary. "The Popular Tradition of Science Fiction Criticism, 1926-1980". In: Science Fiction Studies. (Julho, 1999) Disponível em: http://www.depauw.edu/sfs/ backissues/78/westfahl78.htm Acessado em: 02-05-2009. 
